\title{
On the use of sun trackers to improve maximum power point tracking controllers applied to photovoltaic systems
}

Carles Jaen, Josep Pou, Gabriel Capella, Antoni Arias and Manuel Lamich Technical University of Catalonia (Terrassa, Catalonia, Spain)

jaen@eel.upc.edu, pou@eel.upc.edu, capella@eel.upc.edu, arias@eel.upc.edu, lamich@eel.upc.edu

Abstract- Nowadays power supply systems based on photovoltaic cells have two main drawbacks, even the primary energy is free and renewable. They are: production cost and efficiency. In order to increase their efficiency, it should be interesting that the energy transfer between cells and load was done at maximum level. In this paper the use of a sun tracker system is presented as an additional improvement applied to a photovoltaic installation that works under a maximum power point tracking (MPPT) control technique. A 50W-prototype has been assembled. Some experimental results are also included in order to validate the whole system.

\section{INTRODUCTION}

The European Forum for Renewable Energy Sources (EUROFORES) in its 7th Interparliamentary Meeting on Renewable Energy which took place on October 2007 in Berlin ended with the adoption of the Berlin Declaration 200 by the attending parliamentarians. During this meeting, parliamentarians and experts discussed the most recent developments of European policies in the field of renewable energies.

Regarding the use of renewable energies, that declaration contents an important binding target. In 2020 the $20 \%$ of total energy consumption in the EU will be based on renewable energies.

The European Union has in 2006 (last available data) largely exceeded its White Paper objective in photovoltaics (PV) (3000 MWp in 2010), reaching $3.4 \mathrm{GWp}$ installed capacity [1]. The dynamic German market being of course responsible for approximately $1300 \mathrm{MWp}$. Spain is following with more than $60 \mathrm{MWp}$, Italy with 11.6 $\mathrm{MWp}$, France with 6,4 MWp, Austria with $5 \mathrm{MWp}$, UK with $2.7 \mathrm{MWp}$ and Belgium with 2,1 MWp. The rest of EU is below that. This capacity consists essentially in gridconnected applications, solar roofs, facades and photovoltaic power plants.

Nowadays, PV plants have two main drawbacks: the high cost of cells production and their low energy conversion efficiency. Commercial modules are assembled with efficiency 6 to $16 \%$ depending on their technology. Due to this poor efficiency, strongly dependant on solar radiation level and operating temperature, it is very important to achieve its maximum value. There are two main techniques to get good results. One is 
the use of control techniques, applied to a switching converter, that force the module to operate in the optimal operating point, that it's the maximum power point tracking (MPPT). The other is the use of electro-mechanical equipments. These equipments allow that PV modules keep the best position to obtain the maximum solar-radiation level during the sunny interval of the day. That is the reason they are known as sun trackers. Fig. 1 shows a basic system.

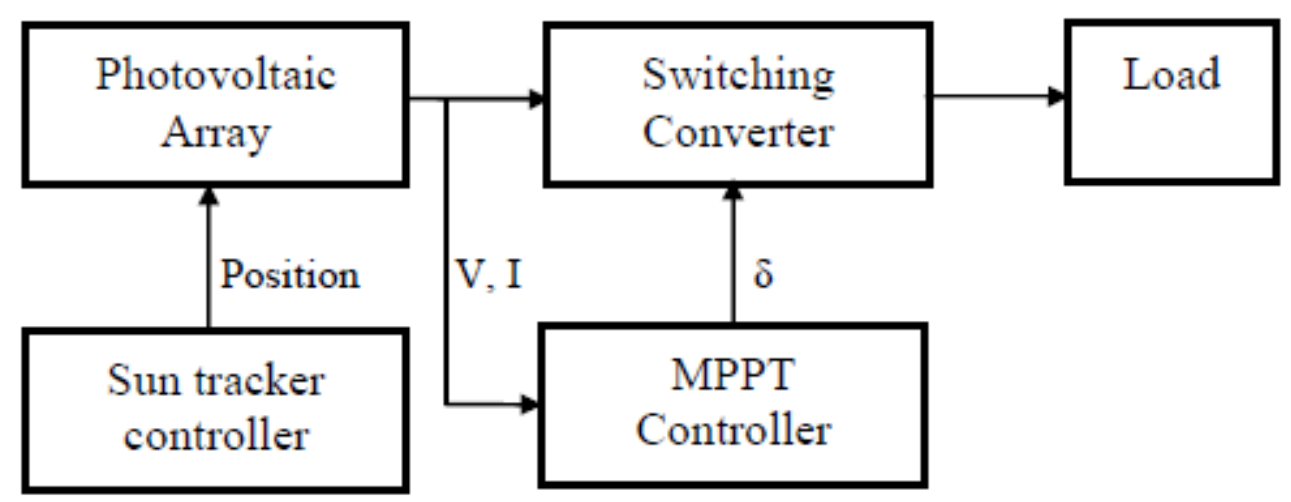

Fig.1. Block diagram of a photovoltaic system including MPPT control and sun tracker equipment

This paper is devoted to present a PV system that includes an MPPT controller and sun tracker equipment. The paper is structured as follows. In section II, the main control techniques are presented. An algorithm based on $\mathrm{P} \& \mathrm{O}$ technique is also full developed. The sun tracker equipment is described in section III. Finally in section IV, some experimental results are also included.

\section{MPPT CONTROL TECHNIQUES}

The operating point at maximum power in systems based on PV modules depends on solar-radiation level, operating temperature and load current. So that's the reason to develop control algorithms in order to ensure that operating point achieves its optimal value.

\section{A. Overview of MPPT control techniques}

Main techniques mostly used are:

1) MPPT based on voltage or current control (VMMPT and CMMPT)

2) Hill climbing $(\mathrm{HC})$

3) Perturbation and Observation (P\&O)

4) Incremental conductance method ( $\mathrm{InC})$

5) Array reconfiguration

6) Fuzzy logic control

7) Neural network

8) Ripple correlation control (RCC)

9) Current sweep 
An excellent paper to read more about those control techniques is [2]. You can find other methods as a modification or combination of those techniques. In this section only the most common techniques will be presented.

Voltage-based MPPT (VMPPT) and current-based MPPT (CMPPT) are known as computational methods [3]. Due to the fact that V-I characteristics of a solar panel are not linear this is modeled using mathematical equations and that model must be valid under different conditions (solar radiation, temperature, drifts, etc). Then partial derivative of power, respect to current, yields to a linear relationship between cells short-circuit current and maximum power current. A similar procedure shows that maximum power voltage and open-circuit voltage have a linear dependence for different solar radiation and operating temperatures. Then those equations are the key to develop CMPPT and VMPPT control techniques.

HC, P\&O are called power feedback methods [4]-[10]. These techniques are based on the regulation of $\mathrm{PV}$ cells array voltage to follow an optimal set point which is the voltage of maximum power working point. This point is periodically tracked and updated in order to achieve a simple mathematical condition, that is $d P / d V=0$, where $P$ and $V$ are respectively output power and output voltage. Due to the power-voltage relationship of a typical PV array, the maximum power point can always be followed if condition $d P / d V$ is kept equal to zero for any solar radiation or temperature. This is possible because to all maximum power points have the same mathematical attribute. This technique as well as $\mathrm{HC}$ technique could present oscillation about the MPP and control problems when the system works under strong changes on solar radiation.

Fig. 2 shows both characteristics, power - voltage and current - voltage of a PV module BP $350 \mathrm{U}$, at $25^{\circ} \mathrm{C}$ of cell temperature, for different solar radiation levels. In Fig. 3 are presented the same characteristics for different temperatures at $1000 \mathrm{~W} / \mathrm{m} 2$ of radiation level.

The incremental conductance $(\operatorname{InC})[8]$ technique is based again on the fact that the derivative of function $p=F(v)$ is zero at the MPP, in any case of PV solar radiation. It's positive on the left of the MPP and negative on the right. All working points are depicted in Fig. 4.

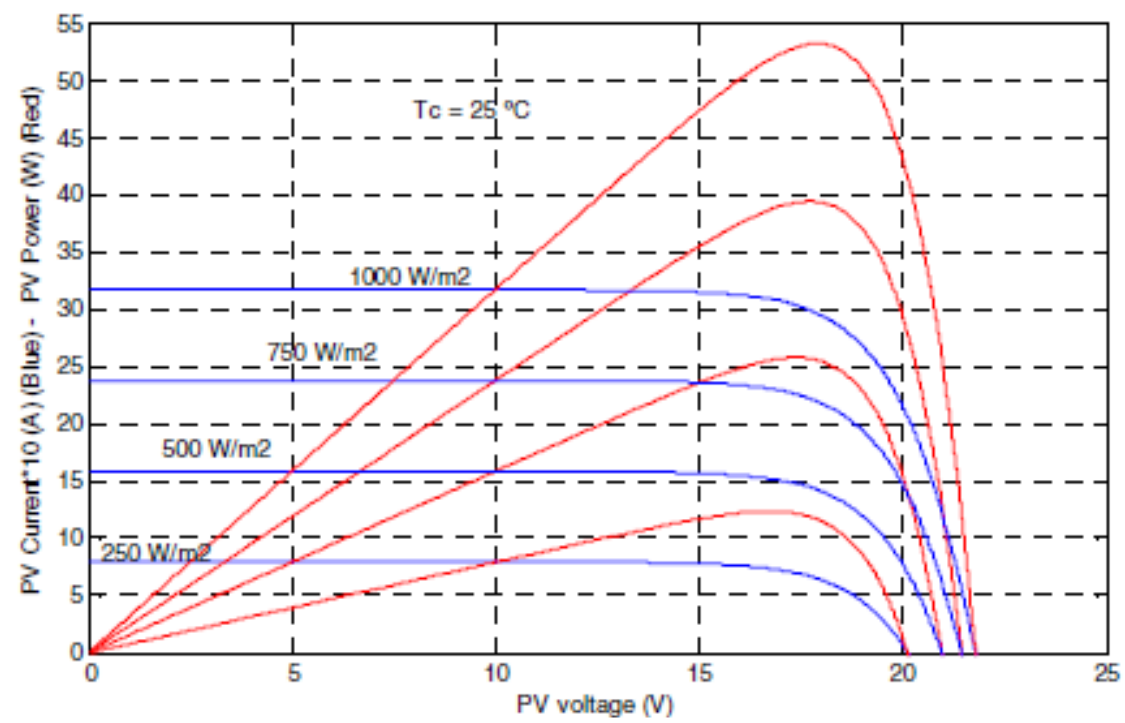

Fig.2. Power - voltage characteristics and current - voltage characteristics of a PV module BP350U for different radiation levels at constant cell temperature 


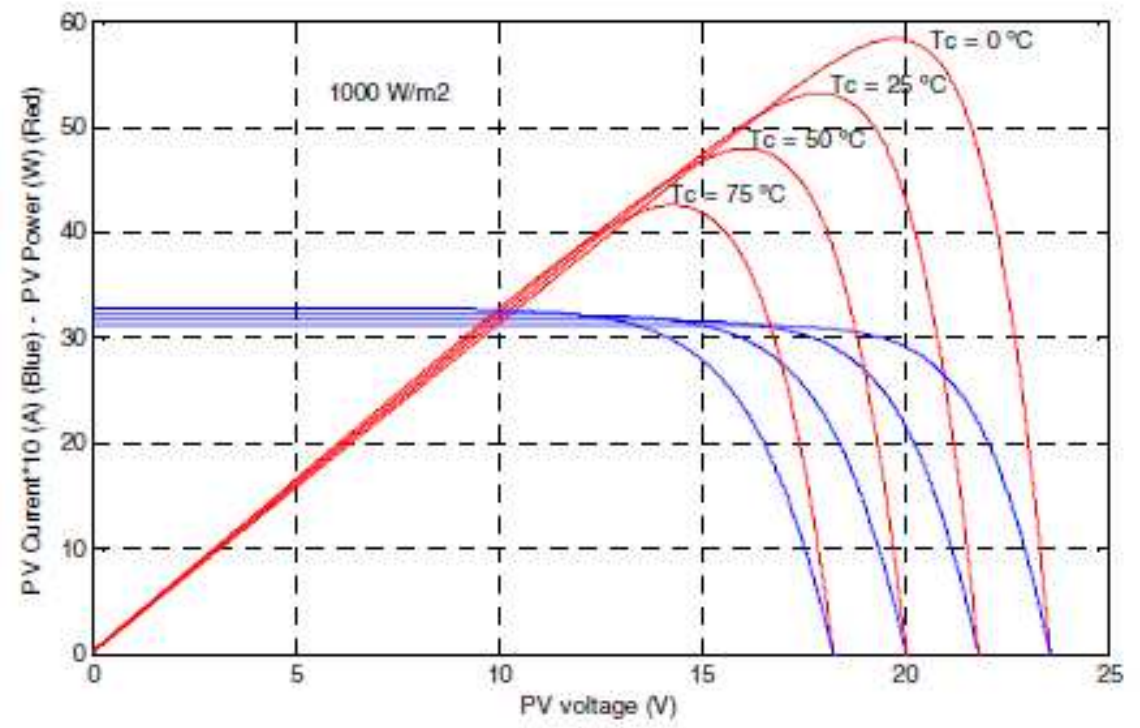

Fig. 3. Power - voltage characteristics and current - voltage characteristics of a PV module BP350U for different cell's temperature at constant radiation level

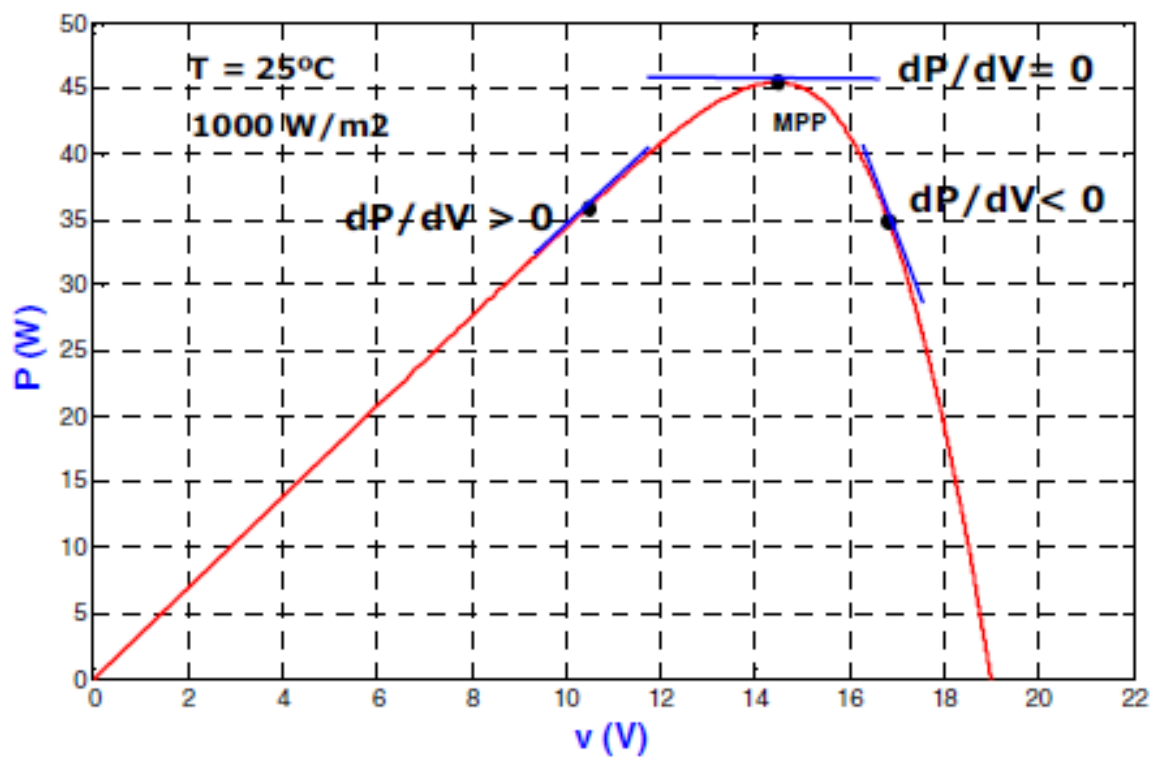

Fig. 4. Different values of $\mathrm{dP} / \mathrm{dV}$ according to the working point.

Due to this, the condition at MPP can be written as in (1), on the left of MPP and on the right of MPP can be shown as in (2).

$\frac{d p}{d v}=\frac{d(v i)}{d v}=i+v \frac{d i}{d v}=0$, or $\quad \frac{\Delta i}{\Delta v}=-\frac{i}{v}$

$\frac{\Delta i}{\Delta v}>\frac{i}{v}$, to the left of MPP

$\frac{\Delta i}{\Delta v}<\frac{i}{v}$, to the right of MPP 
So, MPP can be achieved doing a comparison between the negative instantaneous conductance $(-\mathrm{i} / \mathrm{v})$ and the incremental conductance $(\Delta \mathrm{i} / \Delta \mathrm{v})$ and force both to get the same value. VREF is the reference voltage at which the PV module is constrained to work. When the MPP is achieved, the operation of the PV module is hold at that point (VREF $=$ VMPP) unless a change in $\triangle \mathrm{i}$ is detected. This will mean there is a change in the weather conditions and then in the MPP.

\section{A. Perturb \& Observe technique}

P\&O technique has been selected to implement a MPPT control algorithm due to its simplicity and the possibility to introduce improvements.

As it can be seen in Fig. 2 and Fig. 3 the point of maximum power (MPP) depends on the radiation level and temperature, so the system is not linear and time-variable.

That's the reason to implement the control based on the achievement of $d P / d V=0$ that always is related to the MPP, see Fig. 4.

In this control algorithm PV-output voltage $(v K)$ and Pvoutput current $(i K)$ are sensed. Then power is calculated $(p K)$ and compared with the power value calculated in the previous sample $(p K-1)$ in order to get $\Delta p K$. If the result of $\Delta p K$ is zero the system is working in MPP. Otherwise and according to the sign of $\Delta p K$ and to the sign of $\Delta v K$ the command voltage to control the duty cycle $(\delta)$ of the converter (let's say the perturbation), will be decreased or increased in order to force the working point of the PV module towards the MPP. The algorithm is illustrated in the flowchart shown in Fig. 5.

According to this flowchart four different cases can be found:

- Case 1: $\Delta \mathrm{pK}>0$ and $\Delta \mathrm{vK}>0$

- Case 2: $\Delta \mathrm{pK}>0$ and $\Delta \mathrm{vK}<0$

- Case 3: $\Delta \mathrm{pK}<0$ and $\Delta \mathrm{vK}>0$

- Case 4: $\Delta \mathrm{pK}<0$ and $\Delta \mathrm{vK}<0$

Let's analyze case 1. As it can be seen in Fig. 6 , in this situation $\Delta \mathrm{pK}>0$ and $\Delta v K>0$ and then the working point is located on the left of the MPP and now, in sample $k$, the system is closer to the MPP. So, the new value of command voltage should be higher in order to increase $\delta$ and force the converter to move right its working point towards the MPP.

All possibilities are summarized in Table I. 


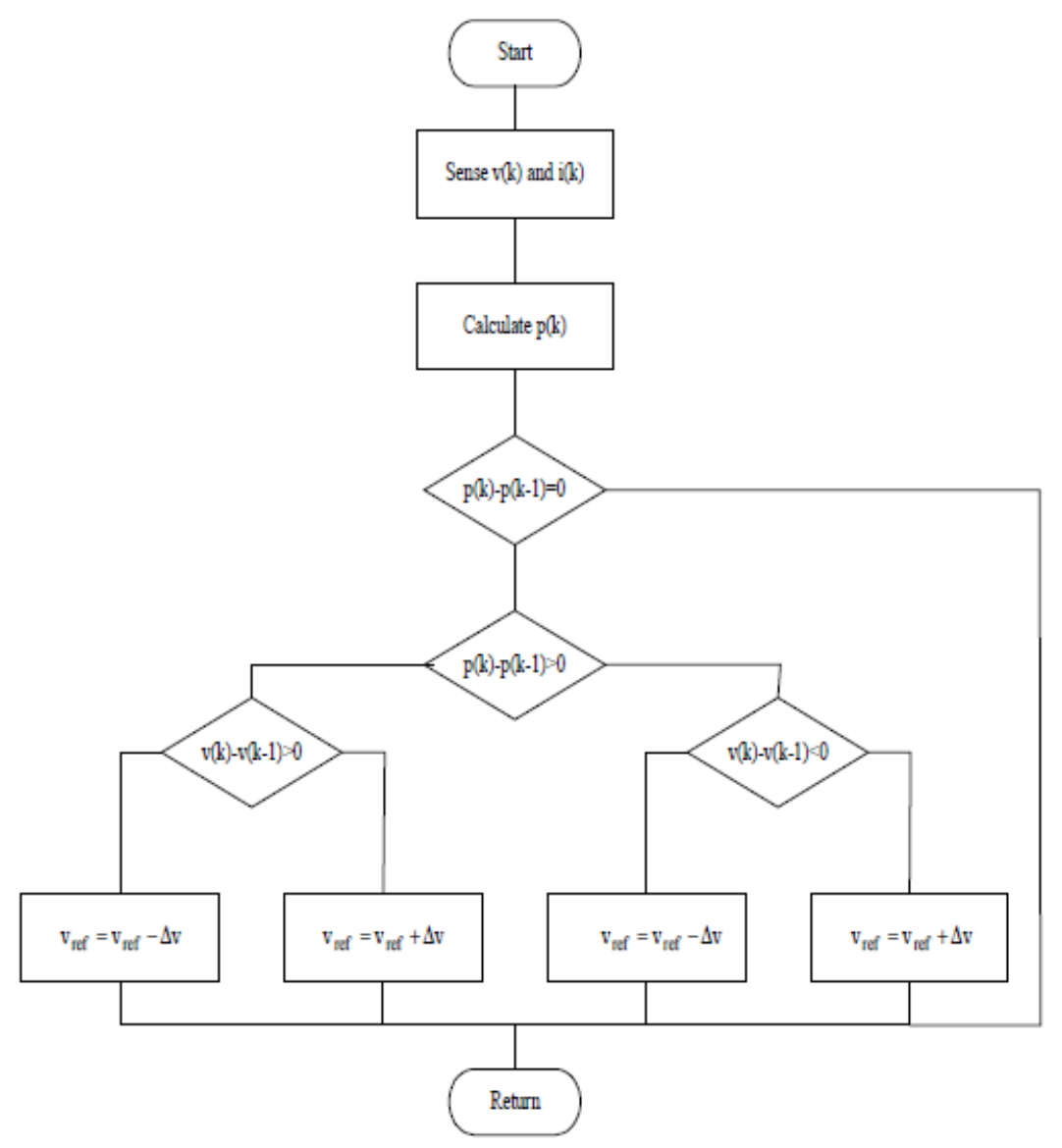

Fig. 5. P\&O algorithm flowchart

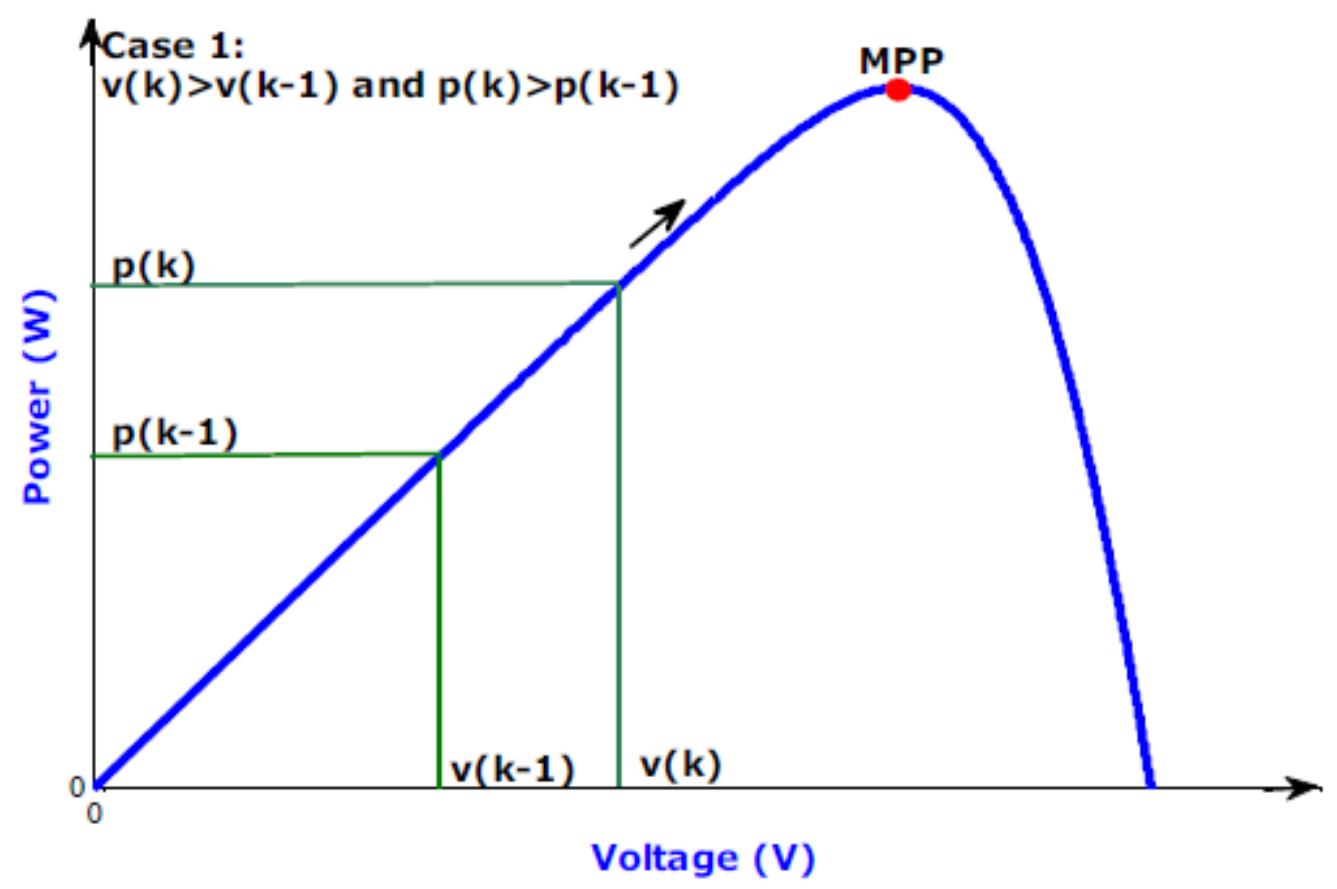

Fig. 6. Case 1 of $\mathrm{P} \& \mathrm{O}$ algorithm 
TABLE I

SUMMARY OF P\&O ALGORITHM CASES

\begin{tabular}{|c|c|c|c|}
\hline Case & Conditions & Position & Control action \\
\hline 1 & $\Delta \mathrm{p}_{\mathrm{K}}>0, \mathrm{v}_{\mathrm{K}}>0$ & Left of MPP & Increase $\delta$ \\
\hline 2 & $\Delta \mathrm{p}_{\mathrm{K}}>0, \mathrm{v}_{\mathrm{K}}<0$ & Right of MPP & Decrease $\delta$ \\
\hline 3 & $\Delta \mathrm{p}_{\mathrm{K}}<0, \mathrm{v}_{\mathrm{K}}>0$ & Right of MPP & Decrease $\delta$ \\
\hline 4 & $\Delta \mathrm{p}_{\mathrm{K}}<0, \mathrm{v}_{\mathrm{K}}<0$ & Left of MPP & Increase $\delta$ \\
\hline
\end{tabular}

\section{SUN TRACKER EQUIPMENT}

The use of sun trackers schemes in conjunction with MPPT control strategies has been demonstrated very useful in order to get higher efficiency in photovoltaic plants [12-17]. The basis of sun tracker equipment is to hold the PV array in the best position regarding the sun location during the sunny time. This can be done by means of single axis (azimuth) or dual axes (azimuth and elevation) systems. The system presented in this work belongs to the last category. The sun tracker is formerly composed by a mechanical mainframe that supports the PV array and its electronic control system that allows its movement in two axes. The only part discussed here will be the electronic equipment. It is powered by means of a $12 \mathrm{~V}-12 \mathrm{Ah}$ lead-acid battery connected to the PV array through a charger.

This provides autonomy of more than 4 days under bad sunny conditions. In this electronic controller, sensors, drives and motors and microcontroller are considered. Additionally, the main program will be summarized.

\section{A. Sensors}

The sensor has been designed with two branches of light dependent resistors (LDR) separated by a perpendicular opaque element. When the plate of LDRs is well positioned regarding the sun, there is no shadow and both branches receive the same amount of sunny light and then have the same resistance. In case of bad positioning of the plate there is a shadow in one branch and then the resistance in both branches will be different. See Fig. 7 and Fig. 8.

In order to provide a voltage proportional to the position, each branch of LDR is connected in series to a fixed resistor. When both voltages have the same value, the $\mathrm{PV}$ mainframe is well positioned. In case of difference of voltage, the position is erroneous and it should be modified. 


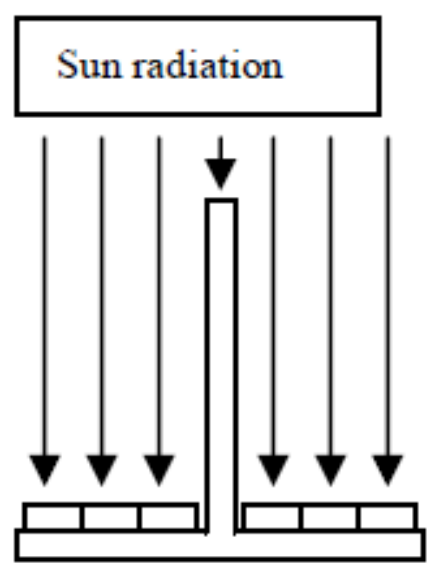

(a)

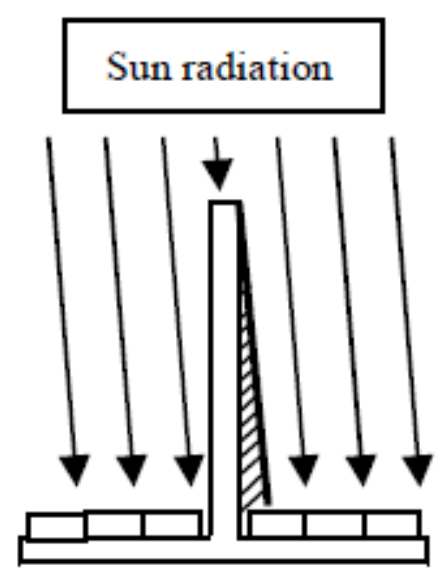

(b)

Fig. 7. Operation of Light sensor:

(a) Good position of PV module (b) Bad position of PV module

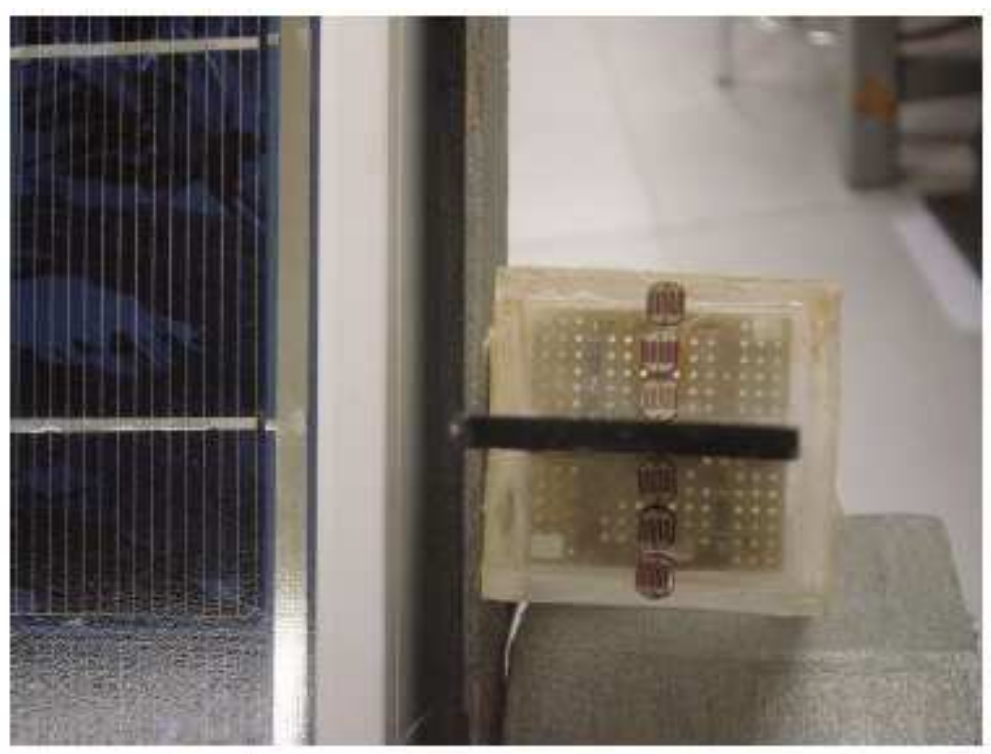

Fig. 8. Elevation light sensor

Due to the fact that the sun tracker controls two axes the system includes one sensor per axis. The four signals delivered by the sensors are sent to the microcontroller.

\section{B. Drives and Motors}

The movement of the PV mainframe is implemented in two axes, and then each axis is connected to a permanent magnet DC motor by means of a gear. In order to have better performance and to get future improvements, each motor is controlled by a DCDC full bridge converter. This converter allows the 4-quadrants operation mode.

\section{Microcontroller}

The four analog signals coming from light sensors are processed by a 8 bitmicrocontroller that includes a multichannel 12 bit ADC. The CPU is full compatible with the assembler programming of 8051 . Four digital signals are used to control both converters.

\section{Programming}


The main program starts with the initialization of variables and ADC configuration. Afterwards, begins a loop that contains routines to check data about azimuth and elevation (Fig.9). Each routine compare the signals coming from each light sensor and drives the motor in the correct direction until they have the same value. This loop is repeated each 5 minutes.

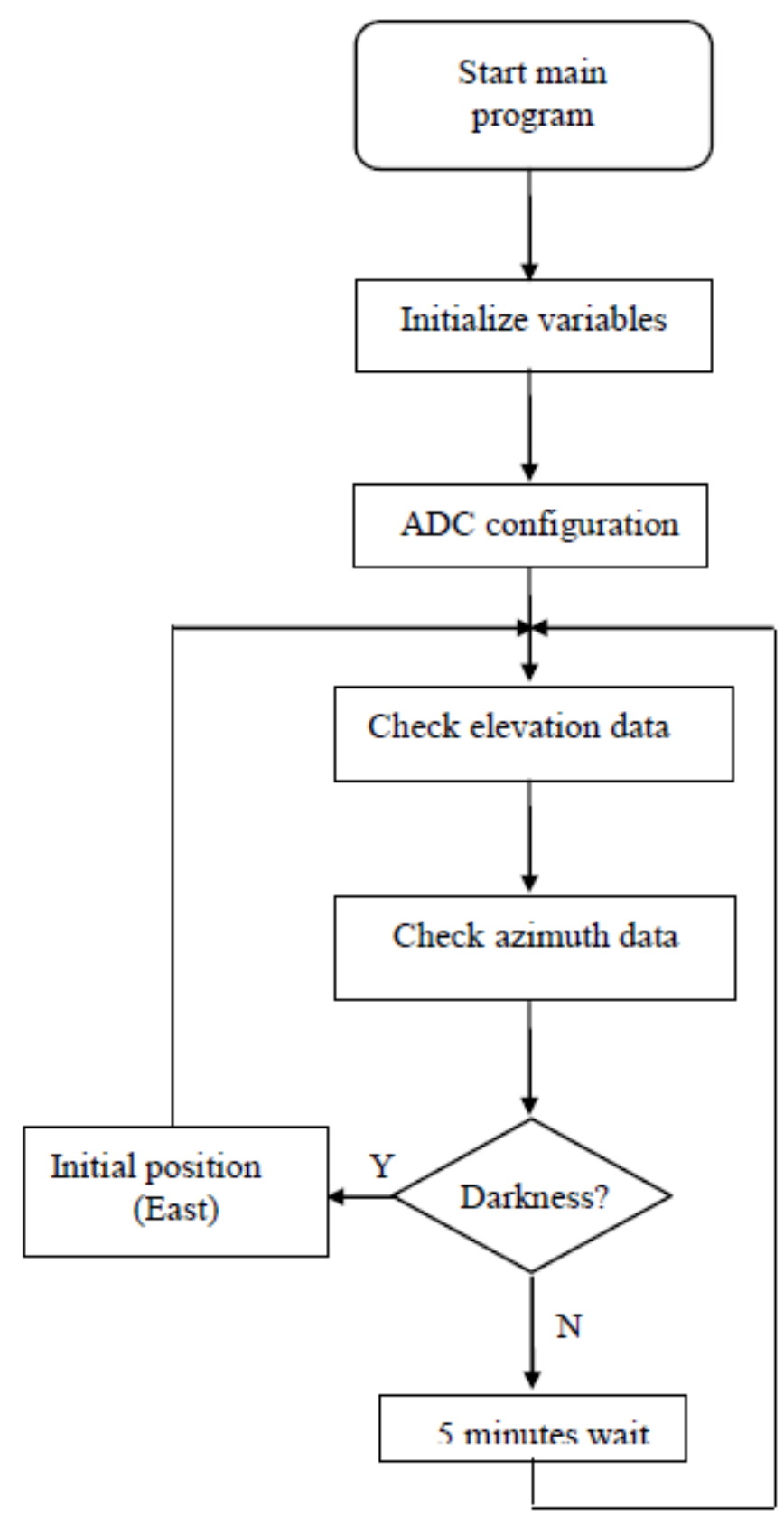

Fig. 9. Flowchart of the main program (sun tracker)

\section{EXPERIMENTAL RESULTS}

To obtain experimental results a complete system has been assembled. Fig. 10 shows the prototype based on a BP350U-50Wp PV module. A 50W-boost converter with the parameters depicted in Table II has also been mounted. The MPPT converter control 
has been implemented by means of an Analog Devices development card that uses an ADuC 812 microcontroller.

TABLE II

PARAMETERS OF BOOST CONVERTER

\begin{tabular}{|c|c|c|c|c|}
\hline $\mathbf{v} \mathbf{N}(\mathbf{V})$ & $\mathbf{L}(\mathbf{m H})$ & $\mathbf{C}(\boldsymbol{\mu F})$ & $\mathbf{R}(\boldsymbol{\Omega})$ & $\mathbf{f}_{\mathbf{S}}(\mathbf{H z})$ \\
\hline PV voltage & 4.8 & 470 & 20 & 3,000 \\
\hline
\end{tabular}

The same card has been used in the sun tracker control. The light sensors have been assembled with two branches of three matched LDR GL7649. In order to compare results, a second twin system has been assembled but without the sun tracker option. See, on the left on Fig.11.

Fig. 12 shows experimental data (power) obtained on May the 30th of 2008. Graphic in blue color is related with the power of first system using the sun tracker, provided that the graphic in red color is according to the second system with fixed position (south oriented). According to these data and comparing both systems the first one delivered $51 \%$ more energy $(\mathrm{Wh})$ than the second.

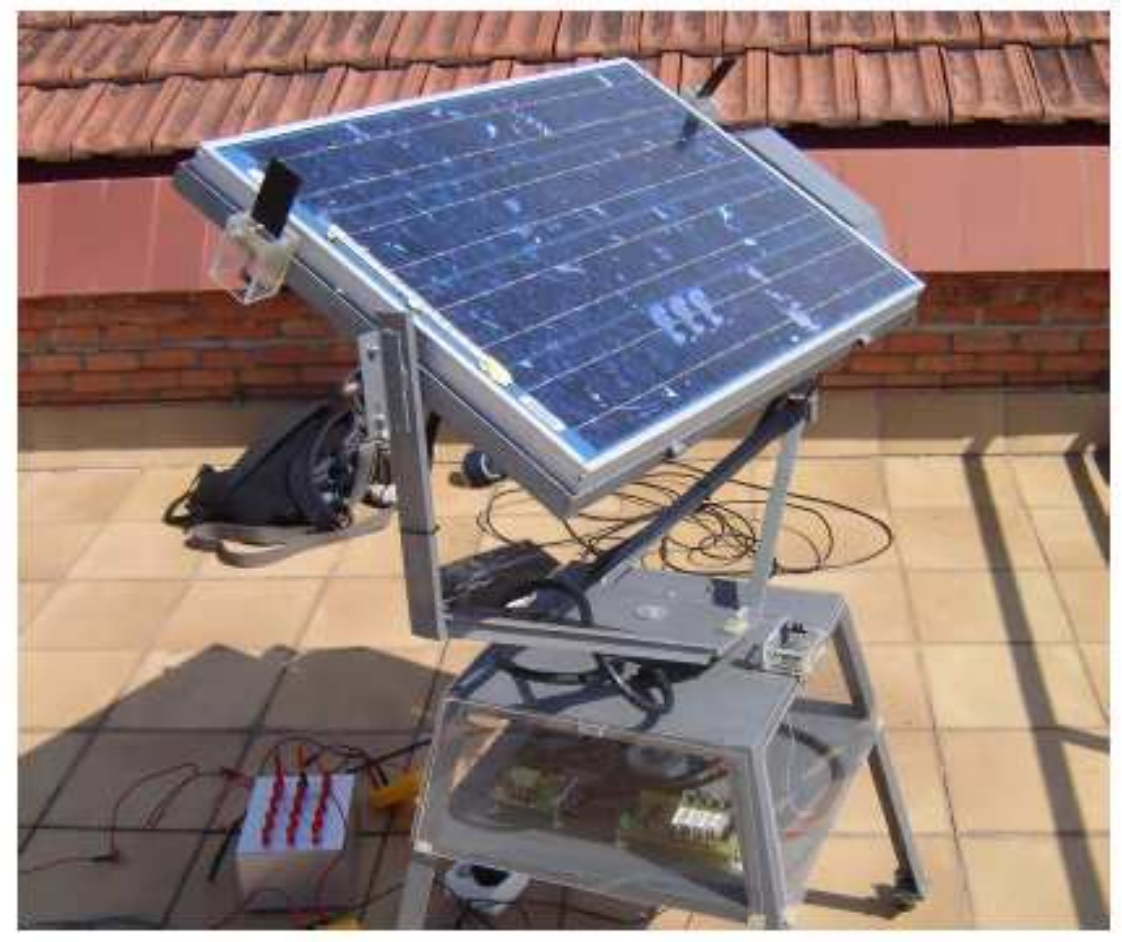

Fig. 10. PV system including sun tracker equipment 


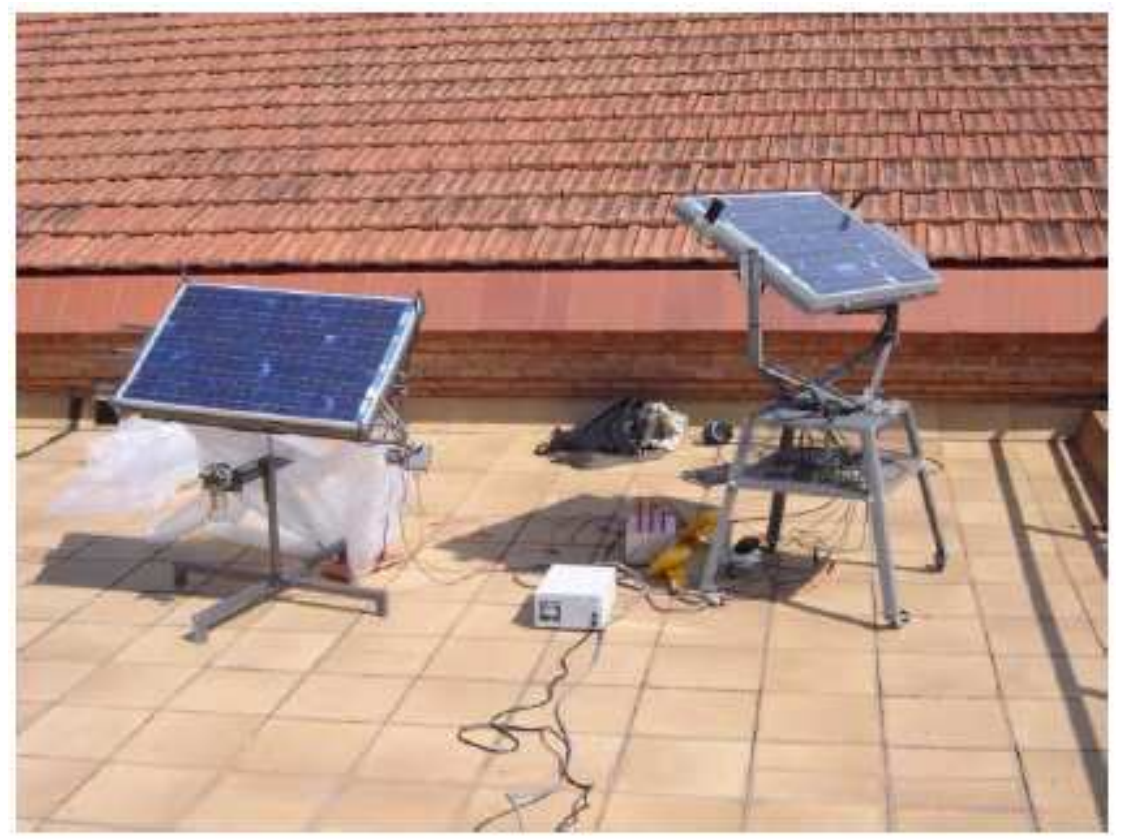

Fig. 11. Both systems working under the same conditions. At left hand, the system with fixed orientation

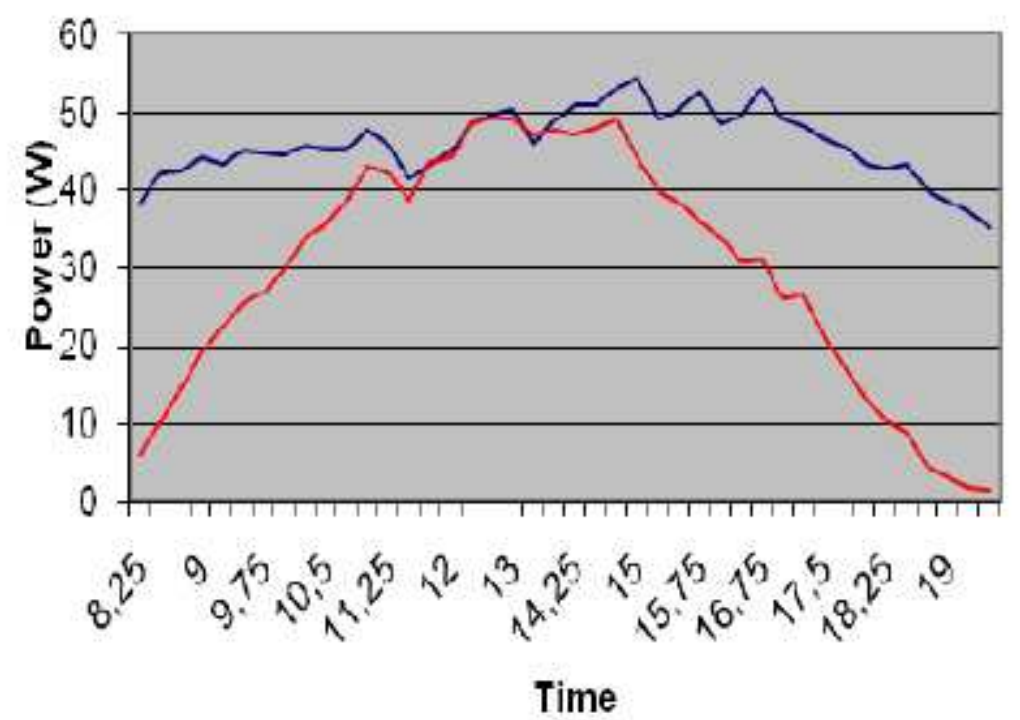

Fig. 12. Power comparison, between system with sun tracker (blue line) and without (red line), done on May the 30th of 2008

\section{CONCLUSIONS}

This paper presents a summary of the main control techniques used to achieve the operating point at maximum power in systems that include a photovoltaic array as a main power supply. An algorithm based on P\&O technique has been developed. Full equipment devoted to achieve a sun tracker function has also been carried out. A whole application, including PV module, boost converter, P\&O controller and sun tracker equipment has been designed and implemented. 
Experimental results show good performance. Comparing data in terms of energy, the plant performances are rather improved by the use of the sun tracker equipment.

Future work will be oriented to develop enhancements in the control algorithms and carry out more experimental results. Additionally, there is a project of an experimental plant based on wind $(1 \mathrm{~kW})$ and photovoltaic $(3.5 \mathrm{~kW})$ energies to be developed during 2009. This plant will be installed on a terrace of the Escuela Universitaria de Ingenieria Técnica Industrial de Terrassa and connected to our research facilities.

\section{ACKNOWLEDGMENT}

This work was supported by the Ministerio de Ciencia y Tecnologia of Spain under Project ENE2007- 67033 - C01.

\section{REFERENCES}

[1] AGORES - A Global overview of Renewable Energy Sources. http://www.agores.org

[2] T, Esram and P.L. Chapman, "Comparison of Photovoltaic Array Maximum Power Point Tracking Techniques," Energy Conversion, IEEE Trans. On, vol. 22, issue 2, June 2007, pp. 439-449.

[3] Mohammad A.S. Masoum, Hooman Dehbonei, and Ewald F. Fuchs, "Theoretical and experimental Analyses of Photovoltaic Systems with Voltage- and Current-Based Maximum Power-Point tracking," IEEE Trans on Energy Conversion, vol. 17, pp 514522, Dec. 2002.

[4] E. Koutroulis and K. Kalaitrakis, "Development of a Microcontroller- Based Photovoltaic Maximum Power Point Tracking Control System", IEEE Trans. Power Electronics, vol. 16, pp.46-54, Jan. 2001

[5] Weidong Xiao, William G. Dunford, "A Modified Adaptive Hill Climbing MPPT Method for Photovoltaic Power Systems", in Conf. Rec., 2004 35th Annual IEEE Power Electronics Specialists Conf., Aachen, pp. 1957-1963

[7] C. Hua, J. Lin, and C. Shen, "Implementation of a DSP- controlled photovoltaic system with peak power tracking", IEEE Trans. On Industrial Electronics, vol. 45, pp. $99-107$, Feb. 1998

[8] C. Hua , C. Shen, "Study of maximum power tracking techniques and control of DC/DC converters for photovoltaic power systems", in Conf. Rec., 29th Annual IEEE PESC, IEEE Computer soc. Press, pp 86-93, New York, 1980

[9] Carles Jaen, Cristian Moyano, Xavier Santacruz, Josep Pou and Antoni Arias, "Overview of maximum power point tracking control techniques used in photovoltaic systems", Proc. of the 15th IEEE International Conference on Electronics, Circuits and Systems, pp 1099-1102, Set. 2008 
[10] C. Hua, J. Lin, and H. Tzou, "MPP Control of a Photovoltaic Energy System", ETEP Vol. 13, no 4, July/August 2003

[11] K. Harada and G. Zhao, "Controlled power interface between solar cells and ac source," IEEE Trans. Power Electron., vol. 8, pp. 654-662, Oct. 1993

[12] M. Taherbaneh, H.G. Fard, A.H. Rezale and S. Karbasian, "Combination of Fuzzy-Based Maximum Power Tracking and Sun Tracker for deployable Solar Panels in Photovoltaic Systems", IEEE International Fuzzy Systems Conference, 2007, pp. 1-6, July 2007

[13] D. Marinescu and C. Marinescu, "Control Optimizing Algorithm for Soft sun Trackers", 2006 IEEE International Conference on Automation, Quality and Testing, pp. 54-57, May 2006

[14] Rong-Jong Wai, Wen Hung Wang and Jung.You Lin, "Grid-connected Photovoltaic Generation System with Adaptive Step Perturbation Method and Active Sun Tracking scheme", IECON 2006 , pp. 224-228, Nov. 2006

[15] Laurentiu Alboteanu, Gheorghe Manolea and Florin Ravigan, "Positioning Systems for Solar Panels Placed in Isolated Areas", Annals of University of Craiova, Electrical Engineering series № 30, 2006.pp. 163-168

[16] J. Cañada, M.P. Utrillas, J.A.Martinez-Lozano, R. Pedrós, J.L. Gomez-Amo and A. Maj, "Design of a sun tracker for the automatic measurement of spectral irradiance and construction of an irradiance database", Renewable Energy, 32 (12), p.2053-2068, Oct 2007

[17] P. Roth, A. Georgiev and H. Boudinov, "Design and construction of a system for sun-tracking", Renewable Energy, 29 (3), p.393-402, Mar. 2004 